\title{
A Transferência de Valor e o Desenvolvimento do Capitalismo: Um Estudo de Caso.
}

\section{Reinaldo A. Carcanholo *}

\section{I - Introdução}

O texto a seguir representa um resumo da tese ${ }^{1}$ que defendemos em 1982, publicada no mesmo ano na América Central 2. Trata-se de uma pesquisa sobre o desenvolvimento do capitalismo em um país da América Latina, dentro de um determinado período.

Nosso trabalho teve pretensóes teóricas e melodológicas. Tratou-se de resgatar a teoria marxista do valor como instrumento fundamental da pesquisa e, para isso, foi indispensável um enorme esforço metodológico que resolvesse questóes vinculadas à relaçăo teoria - realidade concreta.

Assim, acreditamos que este resumo, e especialmente o trabalho completo que a ele corresponde, possam ser do interesse de

*) Professor do Departamento de Economia e do Mestrado em Economia da Universidade Federal da Paraiba, Campus II - Campina Grande.

1) Carcanholo, Reinaldo A., La Transferencia de Valor y el Desarrollo del Capitalismo en Coste Rica. División de Estudios de Posgrado, Facultad de Economia, Universidad Nacional Autónoma de México (UNAM). México, D. F., junio de 1982. (Tesis de Doctorado.)

2) Carcanholo, Reinaldo, Desarrollo del Capitalismo en Costa Rica. San Jose, EDUCA, 1982. 
todos aqueles que se preocupam com questóes metodológicas, especificamente com as assinaladas.

Seguramente será de interesse para aqueles que, tendo se iniciado mais recentemente (ou nem tanto) no conhecimento da teoria, năo sabem ainda, muito bem, o que fazer com ela, năo sabem como utilizá-la para o estudo da realidade concreta e complexa. Desde já diremos a eles que estejam alertas contra aquelas posturas que sustentam serem as dificuldades resultado de excesso de teoria; a questão é justamente a oposta, os problemas surgem, em geral, por conhecimento teórico insuficiente.

Este trabalho nåo servirá para aqueles que insistem em conhecer' a realidade sem antes fazer o esforço teórico necessário; que acreditam que é possivel conhecer o mundo de maneira năo teórica e que năo percebem que entre teoria e realidade, o que existe é a relaçăo abstrato-concreto.

Nosso interesse na publicação deste resumo, divulgando o trabalho mais completo quase dez anos depois, está relacionado com a questão referida. Apesar de termos nos esforçado durante esses anos no ensino da teoria, mesmo no nivel de pós-graduaçăo, năo tivemos oportunidade de travar um diálogo profundo e adequado com estudantes (e mesmo com colegas) sobre as questóes metodológicas que envolvem essa relação entre teoria abstrata e realidade concreta. Isso, sem dúvida, se explica pelo reduzido espaço que ainda se dedica ao estudo na questăo teórica mais geral, da teoria econômica marxista, năo permitindo um grau de conhecimento necessário ao diálogo científico.

Apesar de tudo, mesmo no nosso meio e também entre consultores que nos visitam, existem aqueles que continuam proclamando a necessidade de reduzir-se o tempo dedicado à teoria, para abrir espaço a estudos mais "concretos" e, para isso, năo se envergonham ao defenderem o uso de manuais que abreviem o tempo necessário para "compreender" aqueles conceitos mais importantes e necessários. Se eles chegassem a ler o nosso trabalho, talvez pudessem perceber que nada entendem da teoria, e que nossa postura năo se explica por ausência de interesse sobre a realidade concreta. Ao contrário, é justamente nossa preocupação em interpretar adequadamente o concreto que nos leva a sustentar a relevância do abstrato e a necessidade de um conhecimento profundo sobre ele, especialmente através do estudo da teoria econômica marxista. 
Devemos dizer que nossa pesquisa sobre o desenvolvimento do capitalismo na Costa Rica até 1974/75 e que resultou na redaçăo da referida tese, teve motivaçóes políticas. Além de resgatar a teoria marxista do valor, combater as suas interpretaçoes ricardianas tăo generalizadas nos nossos dias, dar respostas a certas dificuldades que ela aparentemente apresenta, construir certos passos intermediários necessários e de utilizá-la como instrumento fundamental de pesquisa concreta, nosso trabalho teve a intençăo de conhecer a realidade costarriquenha, desde um ponto de vista global, para melhor orientar a prática política transformadora, anticapitalista. Nessa medida, o trabalho teve que incluir um conjunto talvez demasiado amplo de problemas; teve que pretender formular uma interpretaçăo global.

De tudo isso, se algo se alcançou foi, sem dúvida, mostrar que a teoria do valor é fundamental para uma pesquisa concreta, desde um ponto de vista marxista, sobre temas similares ou correlatos. Conseguiu-se fundamentalmente dar respostas a certas dificuldades, logrou-se descobrir e apresentar certas categorias intermediárias e construíram-se indicadores empíricos sobre a evolução da produçăo e da transferência de valor.

Organizaremos esie resumo nas seguintes partes: a questáo teórica (que também envolve aspectos metodológicos), a interpretaçăo sobre o desenvolvimento do capitalismo na Costa Rica e, finalmente, aspectos metodológicos relacionados com a construçăo dos indicadores empíricos. No entanto, para maior facilidade, apresentaremos, antes de mais nada, uma síntese de nossa interpretaçăo sobre o desenvolvimento na Costa Rica.

\section{II - Síntese da interpretação}

Nosso trabalho estuda o desenvolvimento da Costa Rica, com referência especial para o período que se inicia com os primeiros anos da década de 60 , até a metade da década seguinte.

Tal período correspondeu a um novo padrăo de reproduçáo, com destaque para a expansão de um tipo de indústria que consideramos parasitária, pelo fato de que năo fol capaz de produzir mais-valia em volume suficiente para atender a elevada taxa de lucro que exigia. 
A análise alcança, propriamente, até 1974/75, anos em que se manifestaram por primeira vez, e de maneira clara, os limites do padrăo de reproduçăo seguido.

Como já dissemos, nossa tese teve prioritariamente intençăo teórica e metodológica: buscou-se realizar uma pesquisa concreta, sobre o desenvolvimento do capitalismo em um pais do terceiro mundo, utilizando como instrumento explícito e fundamental a teoria marxista do valor. Os aspectos metodológicos consistiam na necessidade de estabelecer os nexos indispensáveis entre o mais abstrato e o mais concreto, o que implicou na necessidade de dispor de indicadores empíricos que permitissem a análise dos fatos concretos.

As principais conclusóes da pesquisa foram as seguintes:

- o novo padrăo de reproduçăo caracterizou-se por uma industrialização parasitária e por uma profunda modificaçăo na estrutura do consumo da grande maioria da populaçăo;

- foi financiado fundamentalmente através do sobre-excedente agroexportador (café) derivado da alta capacidade de geraçăo de renda diferencial geral nas terras produtoras de café do país e secundariamente de mais-valia extraordinária;

- parte dessa renda diferencial pode ser apropriada nacionalmente, apesar de fortes transferências de valor para o resto do mundo;

- secundariamente o valor excedente produzido por camponeses e por outras atividades capitalistas que se expandiram no periodo, fundamentalmente agropecuárias, também contribuiu para aquele financiamento;

- os limites internos desse padrăo de reproduçăo apresentaram-se já nos anos 74/75.

\section{III - Marco teórico}

Considerar a teoria do valor como núcleo central da teoria económica de Marx sobre o capitalismo implica aceitá-la, necessariamente, como instrumento indispensável de qualquer 
pesquisa sobre o desenvolvimento desse sistema, desde um ponto de vista global ou de uma regiáo, como é o nosso caso.

Sua utilizaçăo pressup̧e, antes de qualquer outra coisa, uma interpretação adequada sobre o seu significado, ao mesmo tempo que é indispensável identificar os desvios que derivam de enfoques ecléticos de leituras orientadas por pontos de vista estranhos.

Atualmente a leitura ou interpretaçăo mais difundida sobre a teoria marxista do valor é a ricardiana ou neo-ricardiana. Consiste em entendê-la imediatamenle como uma teoria dos preços relativos, que explica os fatores determinantes da magnitude dos preços relativos ou, simplesmente, uma teoria que estabelece determinada norma de intercâmbio (no caso, associada às quantidades de trabalho contido).

$\mathrm{Na}$ verdade, a teoria do valor de Marx é, antes de qualquer outra coisa, uma teoria da natureza da riqueza na época capitalista, da magnitude da riqueza capitalista produzida e de sua medida imanente. Em primeiro lugar, é uma teoria da produçăo da riqueza na época de domínio do capitalismo.

Se lermos com atençăo O Capital de Marx, especialmente seu primeiro capítulo, veremos que:

a. A riqueza capitalista é ao mesmo tempo duas coisas: é valorde-uso e é valor.

b. A unidade contraditória entre o valor-de-uso e o valor é o que se denomina mercadoria.

c. A mercadoria náo é uma coisa, mas um processo de desenvolvimento que se explica pelo desenvolvimento da contradição entre seus dois pólos: o valor-de-uso e o valor.

d. O desenvolvimento do capitalismo consiste precisamente no processo através do qual o valor (forma histórica da riqueza) subordina cada vez mais o seu oposto, o valor-douso.

è. O limite do capital, nunca alcançável mas sempre desejável por sua lógica, é a destruiçăo do valor-de-uso como aspecto necessário da riqueza capitalista. Análogo a isso, é o processo de desenvolvimento na forma valor (Cf. item 3 do capitulo I d'O Capitah), que consiste na interminável busca 
de um equivalente geral que seja pura representação de valor, sem nenhuma referência ao valor-de-uso.

f. Embora seja certo que, na história concreta, o valor-de-uso jamais poderá desaparecer (ou ser destruído) como aspecto da riqueza capitalista, na unidade contraditória chamada mercadoria, ele é o pólo dominado (a partir de um determinado momento do desenvolvimento mercantil).

g. O valor é o aspecto dominante na mercadoria. A riqueza capitalista năo é, mas trata de ser, exclusivamente valor; e tende a sê-lo:

h. O valor é assim a riqueza na época capitalista; a magnitude daquele é a medida desta.

i. O trabalho abstrato é a substância material do valor, portanto da riqueza capitalista. A dimensão quantitativa daquele, o trabalho socialmente necessário, determina a magnitude desta; o tempo de trabalho socialmente necessário constitui sua medida.

Da mesma maneira que em Smith, para Marx a riqueza envolve uma relaçăo social de domínio. Enquanto para aquele a riqueza é a capacidade que se possui de comprar trabaho alheio (trabalho comandado), para Marx, é o dominio já efetivado sobre o trabalho materializado. Para aquele, a riqueza produzida define-se pela capacidade de apropriaçăo de trabalho no mercado; para Marx, se distingue claramente produção de apropriaçăo de riqueza, de valor. Enquanto para este a exploraçăo flui necessariamente de sua teoria, para Smith a exploraçáo se dissolve e se esconde por detrás do manto nebuloso da aparência e é substituída pela "deduçăo", com a qual se logra a mágica de pensar que, apesar do lucro, todo trabalho é pago.

Dessa maneira, entendido o valor como forma social e histórica da riqueza mercantil ou capitalista e como expressão nas coisas das particulares relaçōes de produção existentes na época mercantil e o valor-de-troca, como a proporção de intercåmbio entre duas mercadorias, a teoria marxista é única. Em Smith, mas muito mais em Ricardo e em todo o pensamento burguês, incluindo Sraffa, a suposta teoria do valor, imediatamente como teoria da determinaçăo dos preços, não é na verdade uma teoria do valor mas do valor-de-troca. 
Entendida como geralmente o é, em especial na atual Interpretaçăo ricardiana, como mera explicaçăo da determinaçăo dos preços, ou uma determinação de norma de intercâmbio, a teoria marxista do valor perde seu poder melodológico e $\theta$ relegada a um mundo abstrato incapaz de relacionar-se com o concreto. Dessa maneira a teoria do valor é relegada ao mundo da metafísica para os mais consequentes, especialmente depois de Sraffa.

Tudo isso năo significa, no entanto, que a teoria de Marx náo seja tarnbém, de alguma maneira, uma teoria dos preços. Mas, a resposta à pergunta "quanto é o preço?" implica uma sérle enorme de mediaçбes, de novas determinaçбes desde a magnitude do valor até a do preço do mercado, passando pela categoria térica intermediária de preço de produçăo.

Sendo assim, em que consiste a utilizaçăo da teoria do valor como instrumento fundamental da pesquisa concreta?

A pesquisa sobre o movimento de uma determinada realidade econômica capitalista, partindo da teoria do valor, supbe a identificaçăo dos ramos fundamentais que produzem riqueza (valor), a compreensáo de sua dinâmica e das formas de produçắo do excedente; supoe também o estudo dos ramos ou setores que se movem devido à apropriaçăo de valor; implica descobrir o processo de articulaçăo concreta que vai se produzindo entre es'ses dois tipos de setores, entre eles a do exterior e explicar os mecanismos de transferência de riqueza (valor) que surgem.

A utilizaçăo da teoria do valor para a pesquisa supbe algumas precisరos indispensáveis: foi necessário ressaltar os conceitos de produçăo, apropriaçăo e transferência do valor. No que se refere, por exemplo, à apropriaçáo pode-se dizer que se trata de um conceito derivado da distribuiçăo e que, em algumas oportunidades, Marx se referiu especificamente a ele. ${ }^{3}$ No entanto, acreditamos que náo teria sido dispensável se Marx houvesse tratado de maneira sistemática e conjunta esses três conceitos (produçăo, apropriação e transferência de valor).

Outra categoria que nos exigiu atençăo foi a de preço de produçăó, pelo fato de que configura um primeiro grupo de determinaçós que nos permite compreender o âmbito da

3) Cl. por exemplo: Marx, Karl, Teorias da Mais-valia, Rio de Janelro, Clvilizaçăo Brasileira, 1980. cap. III, vol. I, p. 72. 
apropriaçăo e também por que é indispensável para a definiçăo de renda diferencial.

Entendemos o preço de produção como um valor transformado, na verdade, como a magnitude do valor apropriável quando da troca da mercadoria, em condiçóes de uniformidade da taxa de lucro. Nessas circunstâncias, o preço de produçăo năo é preço (no sentido de forma simples e relativa do valor quando o equivalente $e$ o dinheiro), nem tampouco preço relativo (valor-detroca em relaçăo a algum numerário qualquer). A unidade de medida da magnitude do preço de produção, da mesma forma que para o valor, é a hora de trabalho.

Uma dificuldade teórica que teve que ser tratada, em razăo de que se sustenta que invalida a teoria marxista do valor, foi a da impossibilidade de que ocorram simultaneamente as duas identidades fundamentais: o valor total e o preço de produçăa total por um lado e, por outro, a mais-valia total e o lucro total.

Já tínhamos irabalhado na soluçăo desse problema antes mesmo do início, propriamente dito, da elaboraçăo da tese, mas dentro de um processo intelectual que concluiu ou, melhor ainda, continuou com ela. Nossa concepção. sobre o assünto pode ser indicada como segue:

a. O resultado do sistema de equaçóes que permite a transformaçăo dos valores em preços de produçăo é que a magnitude da mais-valia total năo é igual à magnitude do lucro total.

b. No entanto, esse resultado formal, paradoxalmente, năo só permite mas é necessário para que se sustente teoricamente a tese de que a mais-valia total é igual ao valor apropriado pelo capital como lucro (segunda identidade fundamental).

c. Note-se que a magnitude da mais-valia é uma magnitude de valor e aparece nos esquemas de transformação como tal.

d. A magnitude do lucro, resultado das equaçóes da transformaçăo, năo é uma magnitude de valor; é uma magnitude de "valor" transformado, mais precisamente, de preço de produçăo.

e. Em termos reais ou materiais, o lucro é um conjunto de valores-de-uso apropriados, destinados ao consumo capitalista ou à acumulação. Portanto, o preço de produção 
desse conjunto de bens que forma o lucro será diferente do valor (supōe-se composiçăo orgânica diferente da média).

f. Entăo, se queremos que a mais-valia total seja igual ao valor apropriado pelos capitais como lucro (segunda identidade fundamental), necessitamos que, em termos numéricos, a magnitude do valor-mais-valia total seja diferente da magnitude do preço de produçáo do lucro. $E$ isso - o que ocorre como resultado das equaçóes da transformaçăo.

g. Em outras palavras, a diferença numérica que se produz entre mais-valia total e lucro total, como resultado da transformaçăo, deve-se exclusivamente ao fato de que a primeira tem como dimensão mensurável o valor $\theta$ a segunda o preço de produçăo. Em termos de magnitude, na verdade, o lucro năo é senăo a mais-valia medida em preços de produçăo.

Um outro aspecto da teoria do valor de Marx que tratamos foi o da determinaçăo do valor social a partir dos valores individuais. Nossa concepçáo sobre o valor nos levou necessariamente à idéia de determinação pela média ponderada em oposiçăo à moda.

Finalmente tivemos que encontrar respostas a uma série de questరes relacionadas com o conceito de renda diferencial. $E$ isso, năo somente por que a teoria da renda da terra é conseqüéncia e complemento necessário da teoria do valor, mas sobretudo pelo fato de que essa categoria estava no desenvolvimento do capitalismo na Costa Rica. Sem as precisбes teóricas que realizamos, a renda da terra, de categoria teórica relevante como instrumento de pesquisa concreta, transformar-se-ia em simples palavra mágica para "explicar" uma realidade pouco entendida.

Em primeiro lugar foi indispensável uma precisåo na forma de definir a renda diferencial. Do livro III d'O Capital parece deduzir-se que ela se define pela apropriaçăo. Isso ocorre pelo fato de que, nesse nivel de abstração, Marx supbe que os preços de mercado correspondem aos preços de produção. Abandonado esse pressuposto veremos que a verdadeira magnitude da renda diferencial difere da apropriação que se pode fazer por esse conceilo. Assim, a renda diferencial não se define pela apropriaçăo. 
Por outro lado, tampouco podemos aceitar que a magnitude da renda diferencial seja produzida, defina-se pela produçăo e isso por que uma parte do valor que se constitui essa renda perfeitamente pode ter sido produzida fora do ramo correspondente e tenha ocorrido uma transferência entre ramos.

Assim, a renda diferencial năo se define pela produçăo, nem tampouco pela apropriação. Ela, como forma do valor, é "gerada" no setor agrícola; o valor que se apresenta sob essa forma pode ou năo ser totalmente apropriado pelo setor e, dessa maneira, pode dar-se transferência. A apropriaçăo dessa renda no setor agrícola pode estar formada tolal ou parcialmente por valor produzido fora dele.

Dessa maneira surge o conceito de GERAÇÃO, que se opre ao de produçăo e de apropriação. Tal conceito, năo desenvolvido por Marx, surge num nivel de abstraçăo mais concreto que o trabalhado por ele. Portanto, náo se trata de uma redefiniçăo da renda diferencial, mas de seu entendimento num nivel mais concreto de análise. Por certo, o conceito de geraçáo também é aplicável à mais-valia (ou lucro) extraordinária, para a qual nem a produçăo, nem a apropriaçăo sáo adequadas. No que se refere ao conceito de mais-valia, sem dúvida, aplica-se-lhe a categoria de produçăo.

Em relaçăo ao conceito de renda diferencial, em dois aspectos mais tivemos que avançar no processo de concreçăo. Tivemos que abandonar as suposiçbes de inexistência de produtores năo capitalistas ("camponeses") e o de inexistência de fronteiras nacionais. Em ambos os casos, mas especialmente no segundo, o novo nivel de abstraçăa implicou no surgimento de novas categorias, ou molhor, de categorias já descobertas por Marx, mas agora mais concretas $\theta$, por isso mesmo, algo distintas.

O abandono da suposiçăo de inexistência de fronteiras nacionais implicou na necessidade de admitir a existência teórica de duas diferentes taxas médias de lucro: uma definida no nivel mundial (ou geral) e outra no nivel nacional. A primeira permitiu definir o que chamamos de preço de produçăo regulador do mercado mundial $e$, a segunda, preço de produçáa regulador do mercado nacional.

Como a renda diferencial define-se a partir do preço de produçáo rogulador do mercado, a existência teórica de dois díerentes preços de produçăo determinou a definiçăo de duas. diferentes rendas diferenciais, a geral a nacional, respectivamente. 
Dessa maneira, a produçăo de café para exportaçăo, num país determinado, gera, ao mesmo tempo, renda diferencial geral e nacional de magnitudes diferentes. Como no nosso trabalho admitimos que a taxa média geral de lucro é superior à taxa nácional, a renda diferencial nacional será menor que a geral. Para esclarecer melhor, só uma parte do valor que constitui a renda diferencial geral gerada na atividade será renda diferencial nacional.

Nossa análise permitiu concluir que a apropriação de renda diferencial na atividade exportadora deve ser, pelo menos, igual à renda diferencial nacional. Se um determinado país apropria-se no mercado mundial de renda diferencial de magnitude superior à renda diferencial nacional gerada em sua atividade exportadora, a diferença constituirá o que chamamos de renda absoluta nacional de monopólio ou sobre-excedente exportador. Será renda absoluta nacional de monopólio a parte dessa diferença (ou toda ela) que seja apropriada na própria atividade exportadora; será sobre-excedente agroexportador a parte transferida a outros setores da economia.

Finalmente, discutimos também a relação entre a apropriação de renda por um país e a fonte correspondente do valor. Concluímos que, apesar de apropriação de renda diferencial por parte de um país exportador de café, apesar da apropriação de renda absoluta nacional de monopólio e de eventual sobre-excedente agroexportador, todo o valor necessário para isso pode ser produzido nacionalmente e, ainda mais, pode inclusive haver, ao mesmo tempo, transferência de valor ao exterior. Dessa maneira, nossa hipótese de que o desenvolvimento do capitalismo na Costa Rica financiou-se com o sobre-excedente cafeeiro, năo implicou no abandono da idéia de que esse valor foi produto da exploração de trabalho local e de que houve transferência de valor (riqueza) ao exterior.

\section{IV - Interpretação sobre o desenvolvimento do capitalismo na Costa Rica}

Apresentaremos a seguir, brevemente, a interprelaçăo sobre o desenvolvimento do capitalismo na Costa Rica, até 
1974/75, resultante da nossa pesquisa. Trata-se, na verdade, de uma sintese do capitulo II da referida tese.

\section{V-Até 1950: o velho modelo}

A economia costarriquenha, em torno de 1950, pode ser caracterizada como muito pouco diversificada, dependente em grau elevado da exportaçăo de somente dois produtos: o café e a banana. As plantaçбes bananeiras constituiam um enclave com muito pouca repercussăo sobre a economia nacional. Sem dúvida nenhuma, as atividades bananeiras de exportaçăo, devido à sua capacidade de gerar renda diferencial, permiliam a produçăo de um enorme excedente, mas que era apropriado quase totalmente pelo capital estrangeiro.

O setor produtivo fundamental foi, portanto, o setor cafeeiro exportador. Outro que deve ser considerado é o agropecuário para consumo interno, que atendia grande parte das necessidades de consumo dos trabalhadores produtivos e alguma parte do consumo dos selores sociais que recebiam renda derivada da mais-valia. Dentro desse setor, o fundamental eram os pequenos camponeses e os camponeses semi-proletários.

A mais-valia ou excedente-valor produzido nos setores produtivos, especialmente no fundamental, era o que garantia o lucro do capital produtivo, o lucro comercial e os juros, depois de deduzidos os gastos improdutivos em bens e serviços, os impostos, as remuneraçбes dos trabalhadores e empregados improdutivos $\theta$ as transferências ao exterior.

Desde outro ponto de vista, poderia se dizer que a mais-valia ou excedente-valor produzido nos setores produtivos, era o que garantia:

- a expansăo (e portanto a acumulaçăo) do setor agroexportador;

- a acumulaçáo do capital comercial;

- a acumulaçăo do capital a juros e a remuneraçăo do capital estrangeiro;

- o consumo da grande, média e pequena burguesias; 
- o consumo dos trabalhadores e empregados improdutivos do setor privado;

- os gastos correntes e os investimentos do governo;

- as transferências ao exterior.

O setor cafeeiro exportador, no período considerado, foi capaz de gerar renda diferencial geral muito superior à renda diferencial nacional. Isso por que as terras marginais usadas no país pelo capital eram mais favoráveis que as marginais em uso no resto dos paises produtores (ou em parte considerável deles).

Nas épocas mais favoráveis do mercado internacional, o país conseguiu apropriar-se de renda muito superior à renda diferencial nacional e, em qualquer época, esteve em melhores condiçoes que os paises que em média utilizavam terra de qualidade inferior.

Durante o periodo que estamos considerando, a grande burguesia agroexportadora, que controlava a melhor terra, o processamento e a exportaçăo de café, foi capaz de apropriar-se diretamente de:

a. a renda diferencial nacional que se gerava em seus próprios cultivos;

b. parte da renda diferencial geral apropriada pelo pais por cima da renda diferencial nacional, devido ao seu monopólio e ao seu poder político;

c. devido ao seu monopólio sobre o processamento e a comercializaçáo do produto, impôs ao cultivador preços de mercado inferiores àquele que garantiria a taxa média nacional de lucro; apropriava-se assim da diferença entre 0 preço de produçăo regulador do mercado nacional e o preço de mercado;

d. em razáo do lucro que esses cultivadores apropriavam-se ser inferior à média nacional, a renda diferenclal apropriada por eles resultava inferior à que geravam; essa diferença também é apropriada pelo grande capital agroexportador (o mesmo ocorre com parte da renda diferencial nacional gerada pelos "camponeses" produtores de café). 
Toda essa apropriaçăo adicional da grande burguesia, por cima da renda diferencial gerada por ela nas terras com cultivos próprios, é renda absoluta nacional de monopólio e é produto da exploração do trabalho nacional. É compartida entre as fraçбes burguesas dominantes: agroexportadora, comercial-importadora e bancária, além de parcelas redistribuidas a fraçбes a elas submetidas.

A reproduçăo desse padrăo de movimento năo exigia, nem tampouco implicava, um rápido processo de acumulaçăo. A incorporação de mais terras e mais força de trabalho era lenta; a introduçáo de novas técnicas ainda mais. O capital que ali funcionava era na verdade uma caricatura de capital, não representava o movimento febril que o caracteriza, năo constituia um verdadeiro capital industrial. Parte considerável do excedentevalor produzido e apropriado nacionalmente se destinava ao desfrute, aos gastos suntuários, não à acumulaçăo.

A estrutura de importaçóes do país estava formada fundamentalmente por produtos industriais suntuários que atendiam a esfera alta do consumo. Devido aos preços superiores aos valores, essas importaçóes implicavam intercâmbio de năo equivalentes que se somava ao resultante dos preços internacionais do café, inferiores ao valor.

Nessas condiçбes, a capacidade que o capital internacional tinha de apropriar-se de valor produzido nos países produtores de café, em razăo dos baixos preços desse produto e dos altos preços dos importados era elevada. No entanto, não se apresentava a possiblidade de uma apropriaçăo diferencial nos diferentes paises cafeeiros (mais ou menos geradores de renda diferencial) desde que as estruturas de suas importaçóes fossem relativamente similares.

A única maneira possível para que o capital internacional aumentasse sua apropriação de excedente no país considerado (excluído o investimento direto na produção nacional), era ampliando o consumo local de importados. O financiamento externo e a apropriaçăo de valor através dos juros constifuía um instrumento pouco relevante.

As limitaçóes assinaladas para a transferência de valor ao exterior, particularmente em um pais no qual as terras utilizadas na produçăo de exportação eram muito favoráveis, determina que esse tipo de padrăo de reproduçãa capitalista em um país chegue a 
ser contraditório com os interesses do capital monopólico internacional, sedento de mais-valia.

\section{VI - O novo padrão de reprodução}

O ano de 1960 pode ser considerado o início do novo padrăo de reproduçăo capitalista no pais. Ele se expressou através de uma expansão industrial de novo tipo e seu conteúdo consistiu na aliança da fração burguesa que vinha progressivamente impondo sua hegemonia com o capital estrangeiro. A nova burguesia costarriquenha renunciou, a partir de então, a qualquer projeto próprio e associou-se de maneira subordinada ao capital imperialista.

A indústria que se desenvolveu graças aos estímulos da lei industrial de 1959 (alta proteção alfandegária e não discriminaçăo em relação à produção de matérias primas importadas) e, posteriormente, graças à entrada de Costa Rica no Mercado Comum Centro-americano, apresentava algumas características que nos interessam particularmente:

a. era fundamentalmente uma indústria não vinculada a matérias primas locais;

b. na maior parte de seus setores, dedicava-se a cumprir exclusivamente as últimas etapas do processo produtivo, importando produtos semi-terminados e insumos muito elaborados;

c. rapidamente consituiu-se em instrumento de imposiçăo de um novo padrăo de consumo na sociedade costarriquenha, modificando inclusive o comportamento consumidor de amplas massas populares, tanto urbanas como rurais; năo pode ser caracterizada como "substitutiva de importaçбes", mas como transformadora do consumo;

d. a indústria doméstica (artesanato e pequena manufatura) foi deslocada pela nova indústria com seu produto mais sofisticado;

e. tratava-se de uma indústria altamente ineficiente devido à tecnologia utilizada, ao pequeno mercado que atendia, à capacidade ociosa que mantinha e ao fato de que só realizava as últimas etapas do processo produtivo; 
f. sua expansão foi apoiada fortemente por uma política estatal coerente de proteçăo e promoção;

g. sua expansăo dependeu, em parte considerável, do capital estrangeiro, direta ou indiretamente, o que significou exigência de altas taxas de lucro.

Por tudo isso, o setor industrial foi incapaz de produzir toda a massa de mais-valia para garantir as altas taxas de lucro que exigia. Dessa maneira sua existência e expansão dependeu da apropriaçăo de excedente-valor transferido por outros setores produtivos. Por essa razăo o chamamos de setor parasitário.

Os setores produtivos que aportaram excedente ao setor parasitário e permitiram assim sua expansăo foram o agroexportador (especialmente café) e, secundariamente, os camponeses dedicados aos produtos de consumo interno. Estes foram incapazes de financiar o setor parasitário graças à sua miséria; o setor agroexportador pôde fazê-lo devido à geração de renda diferencial e de mais-valia extraordinária.

Foi o sistema nacional de preços relativos, como mecanismo fundamental, que garantiu a transferência do excedente-valor necessário ao setor parasitário, que apresentava preços muito elevados. Tal sistema esteve condicionado pela sobrevalorizaçăo da moeda nacional acompanhada por fortes barreiras.

A apropriação do valor produzido nacionalmente através do café exportado foi feita: pelo setor cafeetro exportador, pelos demais setores da economia e pelo resto do mundo. A distribuiçăo entre eles depende de:

- o preço em dólares do café exportado,

- o nivel interno de preços,

- os preços das importações do pais,

- a taxa de câmbio utilizada para pagar os dólares recebidos por exportaçăo de café.

Esses quatro preços foram utilizados para a construção de indicadores empíricos que serviram para a nossa análise.

Outros mecanismos de apropriação de valor produzido na atividade cafeeira pelos demais setores tiveram importância, embora menor que o anterior, como os impostos. 
Durante todo o período 1960 a 1973 observou-se uma fase de grande dinamismo do padrão de reproduçăo. O crescimento econômico, particularmente do setor industrial, foi sustentado, apesar de certas flutuaçð̃es. Ao mesmo tempo observou-se uma grande estabilidade nos preços do país. Só a partir de 1974 que a inflação apresentou-se com certa significaçăo.

Na verdade, nesse período, a capacidade do setor cafeeiro de transferir excedente aos demais setores nacionais, por unidade exportada, foi reduzida se comparada à do período 1950/1957. Portanto, como se explica o grande dinamismo do padrão de reproduçåo? capacidade:

Alguns fatores contribuíram para compensar essa reduzida

a. enorme expansão das atividades e das exportaçð̌es de café, permitindo que, no total, a transferência do periodo fosse superior às anteriores;

b. expansão de outras atividades exportadoras (gado de corte), capazes de gerar forte excedente, superior inclusive ao necesário para financiar a taxa de lucro que exigia;

c. transferência adicional de excedente-valor produzido no campo, em atividades para consumo interno (cereais), graças a uma política de contenção de preços ao produtor;

d. forte entrada no país de capital estrangeiro para investimento direto e empréstimos.

A política econômica do governo foi, durante todo o periodo, a de estimular a expansão das atividades produtivas dominadas pelo capital (café, açúcar, gado, arroz) de apoiar a introdução de modificaçбes tecnológicas. Ampliou-se a rede de estradas, concedeuse o crédito necessário, a assistência técnica, etc. Assim, aprofundaram-se e expandiram-se ainda mais as relaçóes mercantis e capitalistas ao longo de todo o país; ampliaram-se, portanto, as bases da produção de excedente-valor.

Por outro lado, nossa análise indica que a expansão das atividades cafeeiras de exportação ocorreram de tal forma que produziu-se uma reduçăo relativa (ao volume das exportaçóes) de renda absoluta apropriável pelo capital social năo cafeeiro, a 
partir de 58. Por isso, as exigências de expansăo da atividade exportadora para financiar o padrão de reprodução foram maiores.

Essa indispensável expansão produziu progressivamente um esgotamento da massa da força de trabalho disponivel. Tal fato manifesta-se de maneira aguda na época da colheita do café e devido à dificuldade de substituição de trabalho por maior mecanização nessa atividade.

Se somamos ao anterior o fato de que a expansão industrial exigiu uma força de trabalho algo qualificada, entenderemos a política de redistribuição de renda e de concessóes sociais estimulada, no período, pelo partido majoritário no pais (Partido de Liberación Nacional).

Por outro lado, o padrão de reprodução seguido durante o período considerado foi uma maneira através da qual o capital estrangeiro logrou ampliar o excedente, produzido nacionalmente, de que podia se apropriar. Os mecanismos fundamentais dessa apropriação foram: os lucros diretos das empresas estrangeiras instaladas no pais (especialmente na indústria), os altos preços dos insumos e produtos semi-elaborados importados pela indústria e também os bens de consumo que o país importava.

A expansăo desse padrão de reprodução, centrado no desenvolvimento do setor parasitário, encontra seu limite histórico na incapacidade do excedente agropecuário de exportaçăo e dos camponeses de seguir indefinidamente sustentando tal expansão. Esse limite manifestou-se por primeira vez com clareza nos anos 74 e 75.

Com o início de 1974 inagurou-se um período de dificuldades econômicas muito importante no país, que, no final da década, agravaram-se ainda mais. A partir de 1974 a elevação dos preços das matérias primas importadas, dos derivados do petróleo e dos produtos industriais provenientes dos paises mais poderosos, implicou um crescimento muito importante da magnitude do excedente-valor produzido nacionalmente e transferido para o resto do mundo. Essa situaçăo ficou agravada pelo fato de que o preço internacional do café, em 74 e em 75, manteve-se em niveis relativamente baixos. Também o preço de exportação da carne sofreu considerável redução.

Assim, a capacidade de transferência de valor do setor agroexportador ao resto da economia viu-se sensivelmente 
reduzida. Por isso, nesses dois anos, 1974 e 1975, observou-se em Costa Rica uma crise económica acompanhada do início de um período inflacionário bastante severo, se comparado com o movimento dos preços observados nos anos anteriores.

A crise dos anos 74 e 75 năo chegou a produzir uma reduçăo maior no crescimento econômico devido a certos fatores contrários: incremento do volume das exportaçóes e forte entrada de capital estrangeiro, entre outros. Tais fatores lograram atenuar as dificuldades devido ao fato de que o período mais crítico só durou aproximadamente dois anos; já em 1976 os preços do café apresentaram uma substancial elevaçăo.

Esses fatores só permitiram uma pequena sobrevida ao padrăo de reproduçăo capitalista iniciado em 1960. Já em 1980 e início de 1981, quando concluíamos a redaçăo da tese (da que saiu este resumo), podiam ser observados os sintomas concretos de importantes modificaçбes na economia costarriquenha.

Entre as modificaçóes que eram observáveis, nesse momento, cabe destacar (pela importância política e pela perspectiva que antecipara para a vigência da hegemonia da socialdemocracia na Costa Rica) a que se refère à anterior política de concessóes sociais e de distribuiçăo de renda. A tendência à elevação da taxa de mais-valia (através da inflação) não parecia, naquele momento, que fosse algo circunstancial, transitório. Além disso, a burguesia hegemónica, em contraste com os anos 50 , já era forte econômica e politicamente. Já não era necessária, no mesmo grau, a política distributiva como forma de garantir apoio social dos setores populares.

\section{VII - Sobre os indicadores empíricos}

Além das questðoes teóricas e também metodológicas assinaladas anteriormente, consideramos relevante o tema da construçăo e utilizaçăo dos indicadores empíricos de produçăo, apropriaçăo e transferência de valor que se apresenta na tese. Esses indicadores foram utilizados em nossa pesquisa concreta $e$ permitiram precisar nossa interpretaçăo sobre o desenvolvimento do capitalismo na Costa Rica. Digamos algo sobre a questáo.

Evidentemente sabíamos que não era possivel medir o valor produzido nacionalmente nas exportaçóes de café por Costa Rica, o 
valor transferido ao exterior, o valor apropriado nacionalmente pelo setor cafeeiro exportador e pelo resto da economia nacional. Menos ainda seria possível calcular essas magnitudes para o longo período que nos interessava (desde 1950). Essa mediçăo năo só é impossível prática mas também teoricamente.

No entanto, foi possivel construir uma série de indicadores que nos permitiram uma aproximaçăo à variaçăo dessas magnitudes, ao longo do periodo, apesar de limilaçбes que foram assinaladas explicitamente na tese (no anexo, no parágrafo sobre inadequaçăo dos indicadores). seguintes:

Os indicadores construídos e utilizados na pesquisa foram os

- indicador da variação da magnitude do valor total produzido anualmente pelo setor cafeeiro exportador;

- indicador da variaçăo da magnitude do valor total apropriado nacionalmente por exportaçáo de café;

- indicador da variaçăo da magnitude do valor apropriado pelo setor cafeeiro por cada unidade exportada de café e pelo total exportado;

- indicador da variaçáo da magnitude do valor total apropriado pelo resto da economia nacional, pelas exportaçбes de café.

Para a construçăo dos indicadores referidos foram considerados: os volumes anuais exportados de café, o preço em dólares do café exportado, o nivel dos preços internos, o nivel dos preços das importaçðes do pais e a taxa de câmbio utilizada para pagar os dólares recebidos por exportaçăo de café.

Um aspecto importante, do ponto de visla metodológico, é a discussão sobre a inadequação dos indicadores para expressar as verdadeiras variaçóes das magnitudes do valor. Essa questão está relacionada com o que Marx mostra no capítulo I d'O Capital (a mercadoria) sobre a inadequação da forma do valor para expressar - verdadeiro movimento da magnitude do valor. Esse assunto também foi tratado na tese (no seu anexo). 